\title{
WNT5A-ROR2 is induced by inflammatory mediators and is involved in the migration of human ovarian cancer cell line SKOV-3
}

\author{
Somayeh Arabzadeh ${ }^{1}$, Ghamartaj Hossein ${ }^{1 *}$, Zahra Salehi-Dulabi ${ }^{1}$ and Amir Hassan Zarnani ${ }^{2,3}$
}

\author{
*Correspondence: ghossein@ \\ khayam.ut.ac.ir \\ 'Department of Animal Physiology, \\ Developmental Biology Laboratory, \\ School of Biology, College of \\ Science, University of Tehran, \\ Tehran, Iran \\ Full list of author information is \\ available at the end of the article
}

\begin{abstract}
Background: Wnt5A, which is a member of the non-transforming Wht protein family, is implicated in inflammatory processes. It is also highly expressed by ovarian cancer cells. ROR2, which is a member of the Ror-family of receptor tyrosine kinases, acts as a receptor or co-receptor for Wnt5A. The Wnt5A-ROR2 signaling pathway plays essential roles in the migration and invasion of several types of tumor cell and influences their cell polarity. We investigated the modulation of Wnt5A-ROR2 by inflammatory mediators and its involvement in the migration of the human ovarian cancer cell line SKOV-3.
\end{abstract}

Methods: SKOV-3 cells were treated with LPS (lipopolysaccharide), LTA (lipoteichoic acid) and recombinant human IL-6 alone or in combination with STAT3 inhibitor (S1155S31-201) or NF-kB inhibitor (BAY11-7082) for 4, 8, 12, 24 and $48 \mathrm{~h}$. The Wnt5A and ROR2 expression levels were determined the gene and protein levels. Cells were transfected with specific siRNA against Wnt5A in the absence or presence of human anti-ROR2 antibody and cell migration was assessed using transwells.

Results: There was a strong downregulation of Wnt5A expression in the presence of STAT3 or NF-kB inhibitors. Cell stimulation with LTA or IL-6 for $8 \mathrm{~h}$ led to significantly increased levels of Wnt5A (5- and 3-fold higher, respectively). LPS, LTA or IL-6 treatment significantly increased ROR2 expression (2-fold after 48 h). LPS- or LTAinduced Wnt5A or ROR2 expression was abrogated in the presence of STAT3 inhibitor $(p<0.001)$. IL-6-induced Wnt5A expression was abrogated by both STAT3 and NF-kB inhibitors $(p<0.001)$. Although not significant, IL-6-induced ROR2 expression showed a modest decrease when STAT3 inhibitor was used. Moreover, cell migration was decreased by $80 \%$ in siRNA Wnt5A-transfected cells in the presence of anti-human ROR2 antibody $(p<0.001)$.

Conclusions: This study revealed for the first time that inflammatory mediators modulate Wnt5A and ROR2 through NF-kB and STAT3 transcription factors and this may play a role in ovarian cancer cell migration. The results described here provide new insight into the role of the Wnt5A-ROR2 complex in ovarian cancer progression in relation to inflammation.

Keywords: Ovarian cancer, Inflammation, Wnt5A, ROR2, NF-kB/STAT3 signaling pathways, Migration

\section{Biomed Central}

(c) 2016 The Author(s). Open Access This article is distributed under the terms of the Creative Commons Attribution 4.0 International License (http://creativecommons.org/licenses/by/4.0/), which permits unrestricted use, distribution, and reproduction in any medium, provided you give appropriate credit to the original author(s) and the source, provide a link to the Creative Commons license, and indicate if changes were made. The Creative Commons Public Domain Dedication waiver (http://creativecommons.org/ publicdomain/zero/1.0/) applies to the data made available in this article, unless otherwise stated. 


\section{Background}

Ovarian cancer is the seventh most common cancer and the eighth most common cause of cancer deaths among women worldwide [1]. More than $85 \%$ of ovarian cancers are of epithelial origin and the majority of deaths are attributed to the serous carcinoma sub-type [2]. Approximately $80 \%$ of patients with primary disease respond to surgery and chemotherapy, but $60-80 \%$ of these patients will present with recurrent disease 6 months to 2 years post-treatment [2].

The immune system normally causes an inflammatory reaction to kill the abnormal tumor cells. There is increasing evidence that inflammation can also enhance the growth of tumor cells that have "learned" to use the inflammatory process in a way that benefits their development. It has been demonstrated that in addition to associations between inflammatory conditions and particular human tumors, there is a direct link between chronic inflammation and tumorigenesis, particularly through activation of the NF-kB and STAT3 signaling pathways [3].

Wingless proteins, termed Wnt, are a family of cysteine-rich glycoproteins that regulate embryonic development, cell proliferation, differentiation, migration and death [4]. Wnt5A plays essential roles in developmental and physiological processes, including inflammation, but it also plays a role in cancer [5-8]. Its role in inflammation was demonstrated when it was shown to be expressed by monocytes and endothelial cells and modulated by microbial stimulation [7, 8]. Wnt5A primarily activates the $\beta$-catenin-independent pathway of Wnt signaling, which is known to be a non-canonical pathway where ROR2, a member of the Ror-family of receptor tyrosine kinases, may act as a receptor or co-receptor for Wnt5A [5]. Wnt5A-ROR2 signaling involves Disheveled (Dvl), JNKAP-1, the Src family of non-receptor protein tyrosine kinases and $\mathrm{Ca}^{2+}$. It plays essential roles in the migration and invasion and influences the cell polarity of several types of tumor cell [5]. Previous studies on the interactions between ROR2 and Wnt signaling have indicated that ROR2 has multiple functions depending on the cellular context [9]. In recent years, the interaction between ROR2 and Wnt5A in cancer has received great attention. It has been shown that sustained or increased expression of Wnt5A and/ or ROR2 affects the invasive properties of several types of tumor cell, including melanoma, osteosarcoma, renal cell carcinoma, prostate carcinoma, gastric cancer and pancreatic cancer [10-15].

In this study, we aimed to understand whether inflammatory mediators such as lipopolysaccharide (LPS), lipoteichoic acid (LTA) or recombinant human IL-6 (rhIL-6) can modulate Wnt5A and ROR2 expression in the human ovarian cancer cell line SKOV-3. In addition, we assessed the role of STAT3 and NF-kB transcription factors in the regulation of Wnt5A and ROR2 expression and determined whether the Wnt5A-ROR2 complex could influence SKOV-3 cell migration.

\section{Methods}

\section{Cells and treatment}

Cells of the human ovarian carcinoma cell line SKOV-3 were donated by Dr. A.H. Zarnani (Avicenna Research Center, Tehran). The cells were grown in RPMI-1640 medium (Gibco BRL) supplemented with $10 \%$ fetal bovine serum (FBS) and 
penicillin/streptomycin antibiotics obtained from Life Technologies GmbH. Growth conditions were $37^{\circ} \mathrm{C}$ in a $5 \% \mathrm{CO}_{2}$ atmosphere with $90-95 \%$ humidity.

The cells were treated with the following inflammatory mediators: $1 \mu \mathrm{g} / \mathrm{ml} \mathrm{LPS}$; $30 \mu \mathrm{g} / \mathrm{ml}$ LTA (Sigma-Aldrich); or $100 \mathrm{ng} / \mathrm{ml}$ rhIL-6 (Peprotech). Treatment ran for 4, $8,12,24$ and $48 \mathrm{~h}$ before the assessment of Wnt5A and ROR2 expression levels.

In order to assess the role of NF-kB and STAT3 transcription factors on Wnt5A and ROR2 expression, the cells were treated with 5 and $10 \mu \mathrm{M}$ NF-kB inhibitor (BAY117082; Reagentsdirect) or 25 and $50 \mu$ M STAT3 inhibitor (S31-201; Selleck Chemical). The involvement of NF-kB or STAT3 transcription factors on inflammation-induced Wnt5A or ROR2 expression was assessed using $10 \mu \mathrm{M}$ BAY11-7082 or $25 \mu \mathrm{M}$ S31-201, which were added $1 \mathrm{~h}$ before the addition of the inflammatory mediators.

\section{Cell survival assay}

Cell survival was determined using the MTT assay. SKOV-3 cells were seeded at 8000 cells/well in 96-well plates in medium plus $10 \%$ FBS for $24 \mathrm{~h}$. Cells were treated with or without BAY11-7082 $(5,10 \mu \mathrm{M})$ or S31-201 $(25,50 \mu \mathrm{M})$ for $48 \mathrm{~h}$ and cell survival was assessed as previously described [16].

\section{Quantitative RT-PCR}

Total RNA was extracted using RNX-Plus reagent (Cinnagen). Then, $1 \mu \mathrm{g}$ of the RNA was converted to cDNA using RevertAid Reverse Transcriptase (Fermentas). Realtime PCR was conducted using 1x SYBR Premix Ex Taq II (Tli RNaseH Plus; Takara) on an iCyler IQ5 (Bio-Rad) using a continuous fluorescence-detecting thermal cycler (Rotor-Gene Q; Qiagen).

The sequence of the primers used was:

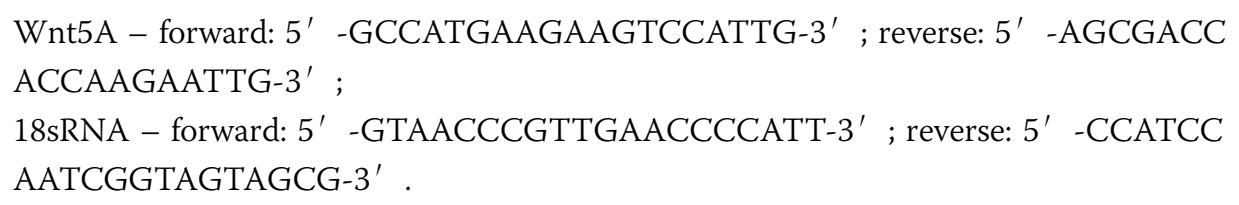

Quantification was performed via the standard curve method using REST-RG software version 3, and the data were normalized relative to the $18 \mathrm{~s}$ RNA housekeeping gene. Experiments were performed in triplicate.

\section{Western blot}

The concentrations and sources of the antibodies were as follows: mouse monoclonal antihuman Wnt5A antibody (1:1500, Abcam), rabbit polyclonal anti-ROR2 (1:1500, Origene) and rabbit polyclonal anti-GAPDH (1:1000, Abcam). Western blot was performed as previously described [16]. Bands were quantified with densitometric analysis, using AlphaEaseFC software. Results were expressed relative to the untreated cells (control, set as 1.0).

\section{SiRNA transfection}

The specific and negative (scramble) controls were Wnt5A knocked down using small interfering RNA (siRNA; ON-TARGET plus SMART pool human Wnt5A, Fisher 
Scientific AG) and non-target siRNAs (ON-TARGET plus SMART pool human NonTarget siRNA, Fisher Scientific AG). Cells treated with only the transfection reagent lipofectamine 2000 (Invitrogen) were used as an additional control. To inhibit endosomal acidification, the cells were pre-treated with $100 \mu \mathrm{M}$ chloroquine (Invitrogen) for $30 \mathrm{~min}$ before transfection. Cells were transfected at 30-50 \% confluence using lipofectamine 2000 to give a final siRNA concentration of $25 \mathrm{nM}$ for $8 \mathrm{~h}$ without FBS and antibiotics. Then, the media were replaced with media containing $10 \%$ FBS plus antibiotics for $48 \mathrm{~h}$.

\section{Migration assay}

Control, siRNA scramble and siRNA Wnt5A-transfected cells were trypsinized after $48 \mathrm{~h}$. The cells were seeded on the upper chamber of an $8 \mu \mathrm{m}$ pore size transwell insert (Costar) at $2.5 \times 10^{4}$ cells/insert in RPMI-1640. The lower chamber contained RPMI1640 culture solution $(600 \mu \mathrm{l})$ plus $10 \%$ FBS. Anti-human ROR2 antibody (Origene) or rhIL-6 $(100 \mathrm{ng} / \mathrm{ml})$ were added to the upper chamber 30 min after seeding and incubated for $5 \mathrm{~h}$ at $37{ }^{\circ} \mathrm{C}$. Non-migratory cells on the upper surface of the membrane were removed and cells were fixed with $4 \%$ paraformaldehyde in PBS and stained in $0.5 \%$ crystal violet. The membranes were mounted on a microscope slide. Migrated cells were counted in ten random fields with a light microscope (Zeiss). Photographs were taken with an AxioCam digital camera (Zeiss). The percentage of migrated cells was calculated. The migration index was expressed relative to control cells (set as $100 \%$ ). All the experiments were carried out three times and results were expressed as the means \pm SD.

\section{Statistical analysis}

Normality of nominal variables was analyzed using the Kolmogorov Smirnov test. Data were analyzed with the statistical software package SPSS 19.0 (SPSS Inc.). We used an unpaired 2-tailed Student's $t$ test or, for comparison of data among groups, 1-way ANOVA test. $p<0.05$ was considered statistically significant.

\section{Results}

\section{Wnt5A and ROR2 expression are induced by LPS, LTA and IL-6}

To study the modulation of Wnt5A-ROR2 signaling by inflammatory mediators, cells were stimulated with LPS, LTA and IL-6 for 4, 8, 12, 24 and $48 \mathrm{~h}$. Real-time PCR analysis showed a significant 1.5-, 3- and 30-fold increase in the Wnt5A mRNA levels after $8 \mathrm{~h}$ stimulation with LPS, LTA and IL-6, respectively (Fig. 1, left panel). These results were confirmed at the protein level for LTA and IL-6 (Fig. 1, right panel). There was no significant increase in the Wnt5A protein level after LPS stimulation (Fig. 1a, right panel). Western blot analysis showed significant increases in the ROR2 protein level: 2-fold in the presence of LPS or IL-6 and 1.5-fold with LTA after $48 \mathrm{~h}$ (Fig. 2).

\section{Wnt5A-ROR2 expression is mediated by NF-kB and STAT3 signaling pathways}

NF-kB and STAT3 have been implicated in the regulation of Wnt5A transcription $[17,18]$. However, the role of these transcription factors in the regulation of Wnt5A in human ovarian cancer remains unknown. We assessed the cytotoxic effect of BAY11-7082 as an NF-kB inhibitor (5 and $10 \mu \mathrm{M})$ or S31-201 as a STAT3 inhibitor 

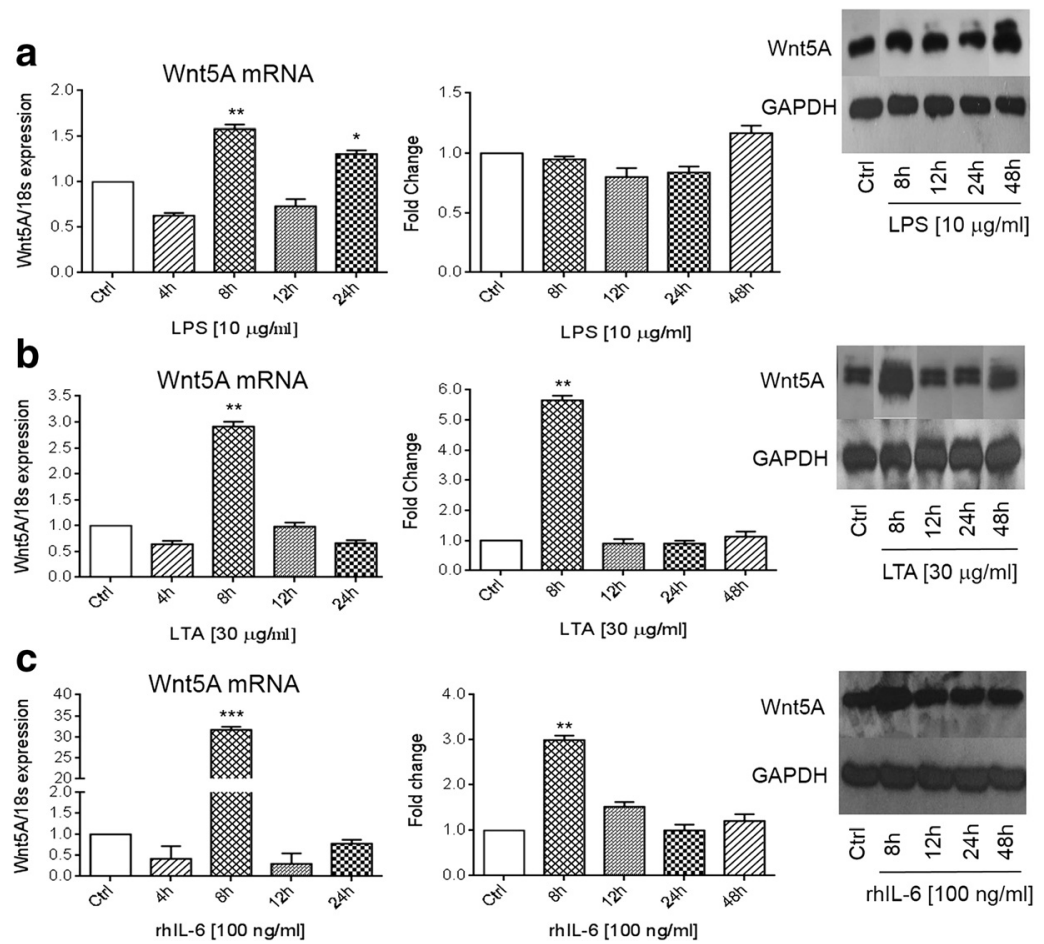

Fig. 1 Wnt5A expression induced by LPS, LTA and IL-6. SKOV-3 cells were treated with $1 \mu \mathrm{g} / \mathrm{ml}$ LPS (a); $30 \mathrm{mg} / \mathrm{ml}$ LTA (b) or $100 \mathrm{ng} / \mathrm{ml} \mathrm{IL-6} \mathrm{(c)} \mathrm{for} \mathrm{the} \mathrm{indicated} \mathrm{times.} \mathrm{The} \mathrm{left} \mathrm{panels} \mathrm{show} \mathrm{normalized} \mathrm{values}$ (means $\pm \mathrm{SD}$ ) from three independent quantitative PCR analyses for Wnt5A expression. Data were normalized related to $18 \mathrm{~s}$ RNA as the internal control. The right panels show normalized values (means \pm SD) from three independent western blots for Wnt5A. The western blots represent one of three independent experiments. GAPDH levels were used as the internal control. ${ }^{*} p \leq 0.05 ;{ }^{* *} p \leq 0.01 ;{ }^{* * *} p \leq 0.001$ as compared with the control (Ctrl)

$(25$ and $50 \mu \mathrm{M})$ on SKOV-3 cells. There were $37 \%(p<0.05)$ and $50 \%(p<0.01)$ decreases in cell viability in the presence of 5 or $10 \mu \mathrm{M}$ BAY11-7082, respectively. Similarly, there were $40 \%(p<0.05)$ and $50 \%(p<0.01)$ decreases in cell viability in the presence of 25 or $50 \mu \mathrm{M}$ S31-201, respectively (Fig. 3a). Western blot analysis showed that Wnt5A expression decreased in the period from 8 to $24 \mathrm{~h}$ in the presence of BAY11-7082 (Fig. 3b and d). In the presence of S31-201, Wnt5A expression decreased in the period from 12 to $48 \mathrm{~h}$ (Fig. 3c and d). Based on these data, the effect of inhibitors on ROR2 expression level was assessed at 24 and $48 \mathrm{~h}$. The results showed that BAY11-7082 led to a $30 \%$ decrease in ROR2 at $24 \mathrm{~h}(p<0.05)$, while S31-201 abrogated ROR2 expression $(p<0.001)$ at $48 \mathrm{~h}$ (Fig. 3e and $\mathrm{f}$ ).

\section{NF-kB and STAT3 signaling pathways are implicated in inflammation-induced Wnt5A and ROR2 expression}

NF-kB and STAT3 are known to mediate the expression of many genes that influence growth and inflammation and are often upregulated in cancer [3]. Therefore, we assessed the effect of inflammatory mediators in the presence or absence of above-mentioned NF$\mathrm{kB}$ and STAT3 inhibitors. LPS- and LTA-induced Wnt5A expression was abrogated with the STAT3 inhibitor (Fig. 4a and b, upper and lower panels) and IL-6-induced Wnt5A expression was modulated by both STAT3 and NF-kB signaling pathways (Fig. 4c, right and 


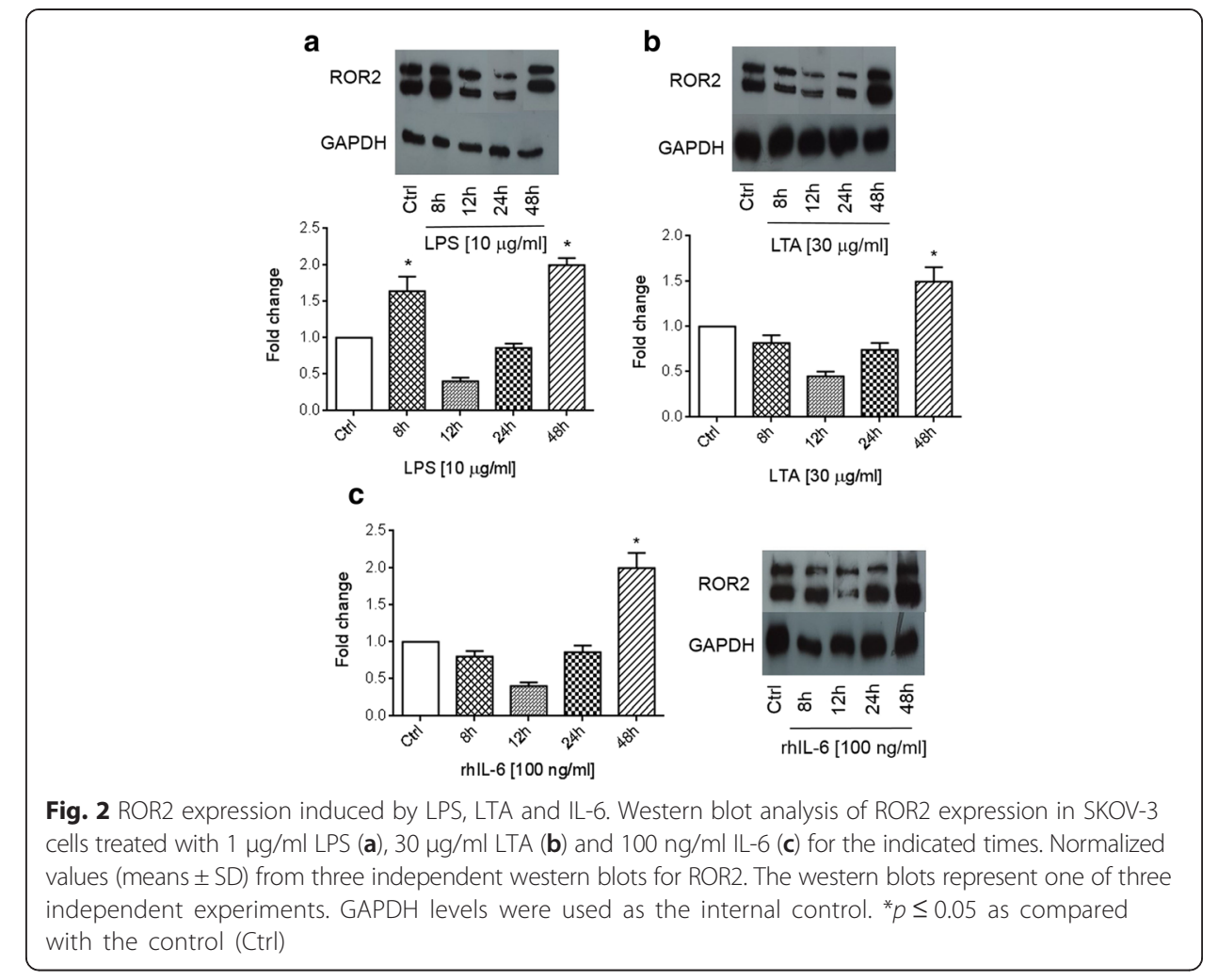

left panels). Similarly, LPS- and LTA-induced ROR2 expression was abrogated in the presence of the STAT3 inhibitor (Fig. 5a and b, right and left panels). IL-6-induced ROR2 expression remained unchanged in the presence of the inhibitors (Fig. 5c).

The Wnt5A-ROR2 complex is involved in migration of the SKOV-3 cell line

Our previous study [16] showed that SKOV-3 cell migration increased in Wnt5Aoverexpressing SKOV-3 cells. Having shown that rhIL-6 led to increased levels of Wnt5A expression (Fig. 1), we assessed whether Wnt5A may be implicated in IL-6induced cell migration. Wnt5A expression level was modulated using siRNA Wnt5A transfected cells that showed $70 \%$ decreased Wnt5A levels (Fig. 6a). Moreover, Wnt5A knockdown cells were used for the migration assay in the absence or presence of rhIL6. There was 1.8- fold increase in cell migration with rhIL-6 $(P<0.05)$, whereas Wnt5A knockdown cells that were treated with rhIL-6 showed a $50 \%$ decrease in cell migration relative to the control ( $p<0.001$; Fig. $6 \mathrm{~b}$, upper and lower panels).

Previous studies showed that Wnt5A requires ROR2 expression to mediate the migration of cells during mammalian palate development [19] and that increased expression of Wnt5A led to increased melanoma cell motility [10]. Therefore, it was tempting to speculate that Wnt5A-ROR2 may be involved in the migration of ovarian cancer cells. The migration assay revealed that knockdown of Wnt5A expression influenced cell migration: there was a $67 \%$ decrease in cell migration in siRNA Wnt5Atransfected cells compared to the controls $(p<0.01)$. Moreover, adding anti-ROR2 antibody in the culture media led to a $29 \%$ reduction in cell migration in the controls and an $80 \%$ decrease in cell migration in siRNA Wnt5A-transfected cells (Fig. 7, upper and 

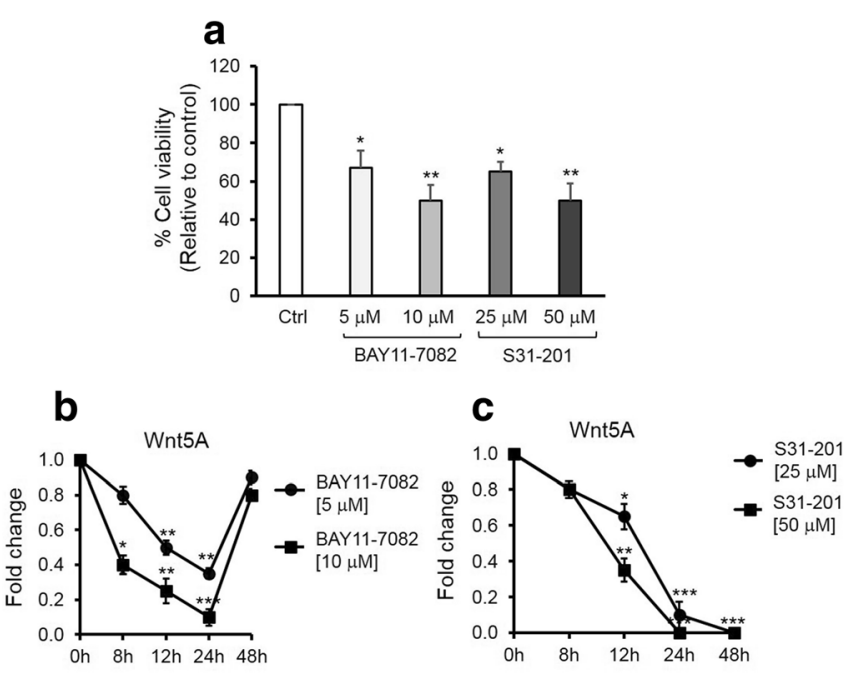

d

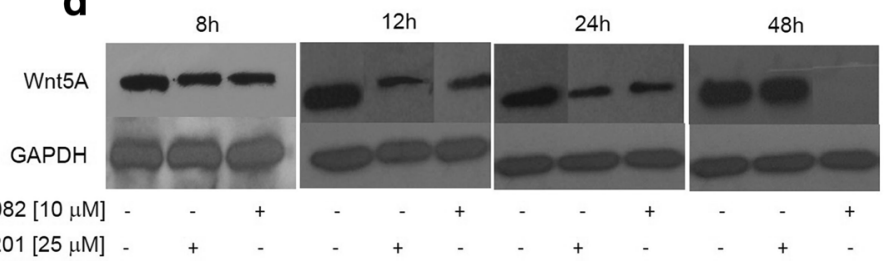

\section{e}

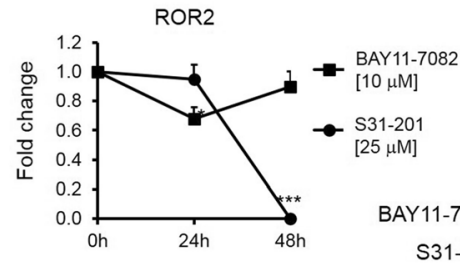

\section{f}

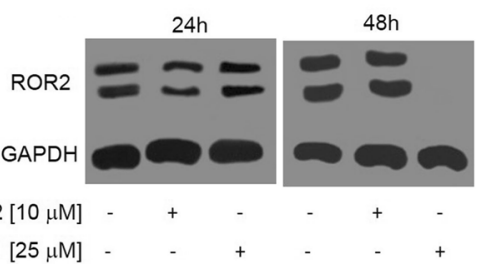

Fig. 3 NF-kB and STAT3 inhibitors alter SKOV-3 cell viability and affect Wnt5A and ROR2 expression. a - MTT assay of cell viability in the presence of BAY11-7082 as an NF-kB inhibitor $(5,10 \mu \mathrm{M})$ or S31-201 as a STAT3 inhibitor $(25,50 \mu \mathrm{M})$. b - Normalized values (means \pm SD) from three independent western blots for Wnt5A in the presence of BAY11-7082 for the indicated times. c - Normalized values (means \pm SD) from three independent western blots for Wnt5A in the presence of S31-201 for the indicated times. D - Western blot analysis of Wnt5A in cells treated with BAY11-7082 $(5,10 \mu \mathrm{M})$ or S31-201 $(25,50 \mu \mathrm{M})$ for the indicated times. The western blots represent one of three independent experiments. E - Normalized values (means \pm SD) from three independent western blots for ROR2 in the presence of BAY11-7082 or S31-201 for 24 and 48 h. F- Western

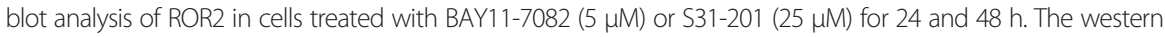
blots represent one of three independent experiments. GAPDH levels were used as the internal control. ${ }^{*} p \leq 0.05$; ${ }^{* *} p \leq 0.01 ;{ }^{* *} p \leq 0.001$ as compared with the control (Ctrl)

lower panels). These results showed that Wnt5A mediates SKOV-3 cell migration through ROR2 signaling.

\section{Discussion}

It has been demonstrated that Wnt5A is involved in inflammatory processes but its role in ovarian cancer in relation to inflammation remains unknown. Several studies showed the role of Wnt5A in inflammation-related diseases $[20,21]$ and highlighted the relation between the Wnt5A signaling pathway and cytokine production in cells of monocytic lineage [7, 22], neutrophils [23] and endothelial cells [24]. In the ovary, Wnt5A 


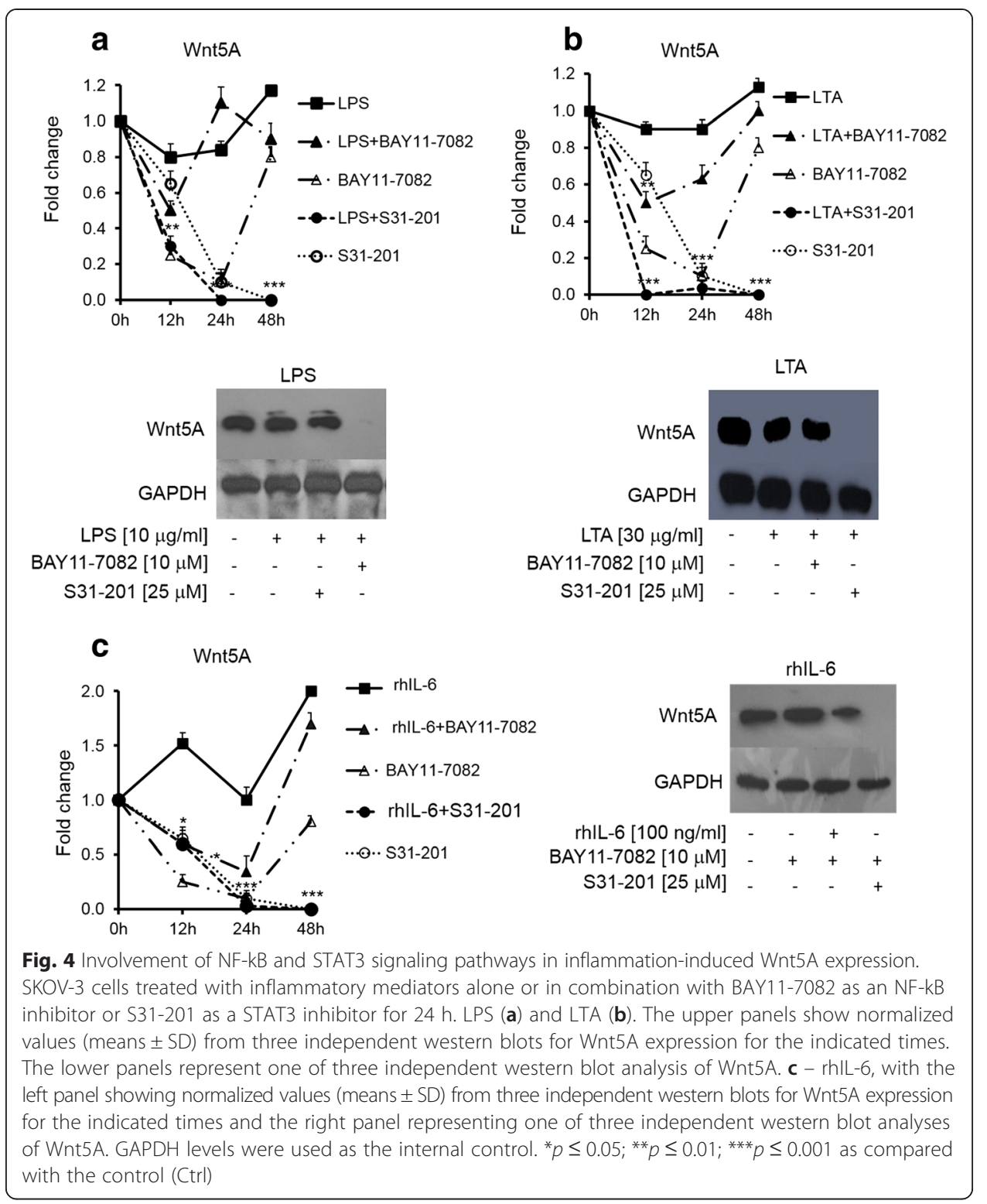

acts as a pro-inflammatory factor in the ovarian granulosa cells of women with polycystic ovarian syndrome [25].

In support of a role for Wnt5A in inflammation, previous studies showed that NF-kB has been implicated in the regulation of Wnt5A transcription [26, 27]. A STAT3binding site was not identified within the human Wnt5A exonic regions but tandem STAT3-binding sites with 11-bp spacing were identified within the conserved region in intron 4 [18]. Wnt5A activity in pathological inflammation has been linked to Toll-like receptors (TLRs), a family of transmembrane signaling proteins that trigger the innate immune response [7].

In addition, it has been reported that healthy ovary tissue, human epithelial tumors and numerous ovarian cancer cell lines, including SKOV-3 cells, express TLR2, -3, -4 and -5 and IL- 6 receptor $[28,29]$. It was suggested that activation of these receptors 

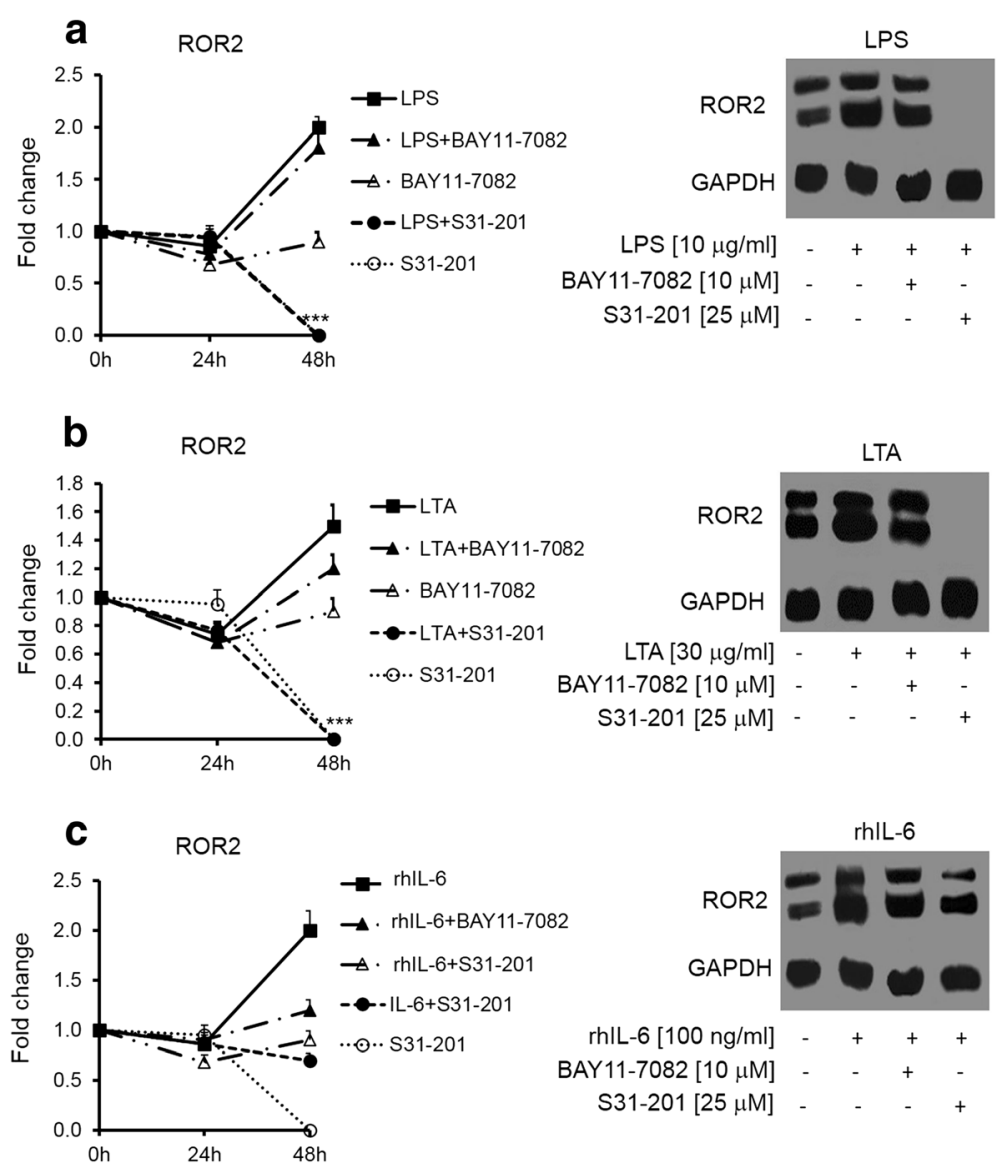

Fig. 5 Involvement of NF-kB and STAT3 signaling pathways in inflammation-induced ROR2 expression. The left panels show normalized values (means \pm SD) from three independent western blots for ROR2 expression for the indicated times and the right panels represent one of three independent western blot analyses of ROR2 in SKOV-3 cells treated with LPS (a); LTA (b) and rhIL-6 (c) alone or in combination with BAY11-7082 or S31-201 for $48 \mathrm{~h}$. GAPDH levels were used as the internal control. ${ }^{* *} p \leq 0.001$ as compared with the control (Ctrl)

initiates NF-kB and/or STAT3 activation, which may constitute a mechanism by which the cancerous epithelial cells can manipulate inflammatory pathways to encourage tumor growth [28-30]. It is hypothesized that constitutive NF-kB signaling defines a subset of ovarian cancer, susceptible to therapeutic targeting of this pathway [31, 32].

Our previous study and other studies demonstrated a promoting role of Wnt5A in epithelial ovarian cancer [16, 33-36]. However, one study reported that Wnt5A supresses epithelial ovarian tumor formation by promoting surface epithelial cell senecsence [37]. To date, this has not been confirmed further. ROR2 may be a receptor or co-receptor of Wnt5A in a context-dependent manner [6]. It showed high expression in osteosarcoma [11] and renal cell carcinoma [12] and its high expression in neuroblastoma was correlated with poorer survival [38]. To the best of our knowledge, there are no data about the modulation of Wnt5A-ROR2 by inflammatory mediators in ovarian cancer cells. Here, we showed upregulation of Wnt5A expressionby LPS, LTA and to a larger exent by IL-6 in SKOV-3 cells.

In ovarian cancer, the increased activity of NF-kB has been reported to confer resistance to chemotherapeutic agent-induced apoptosis [39, 40]. Moreover, it has been 

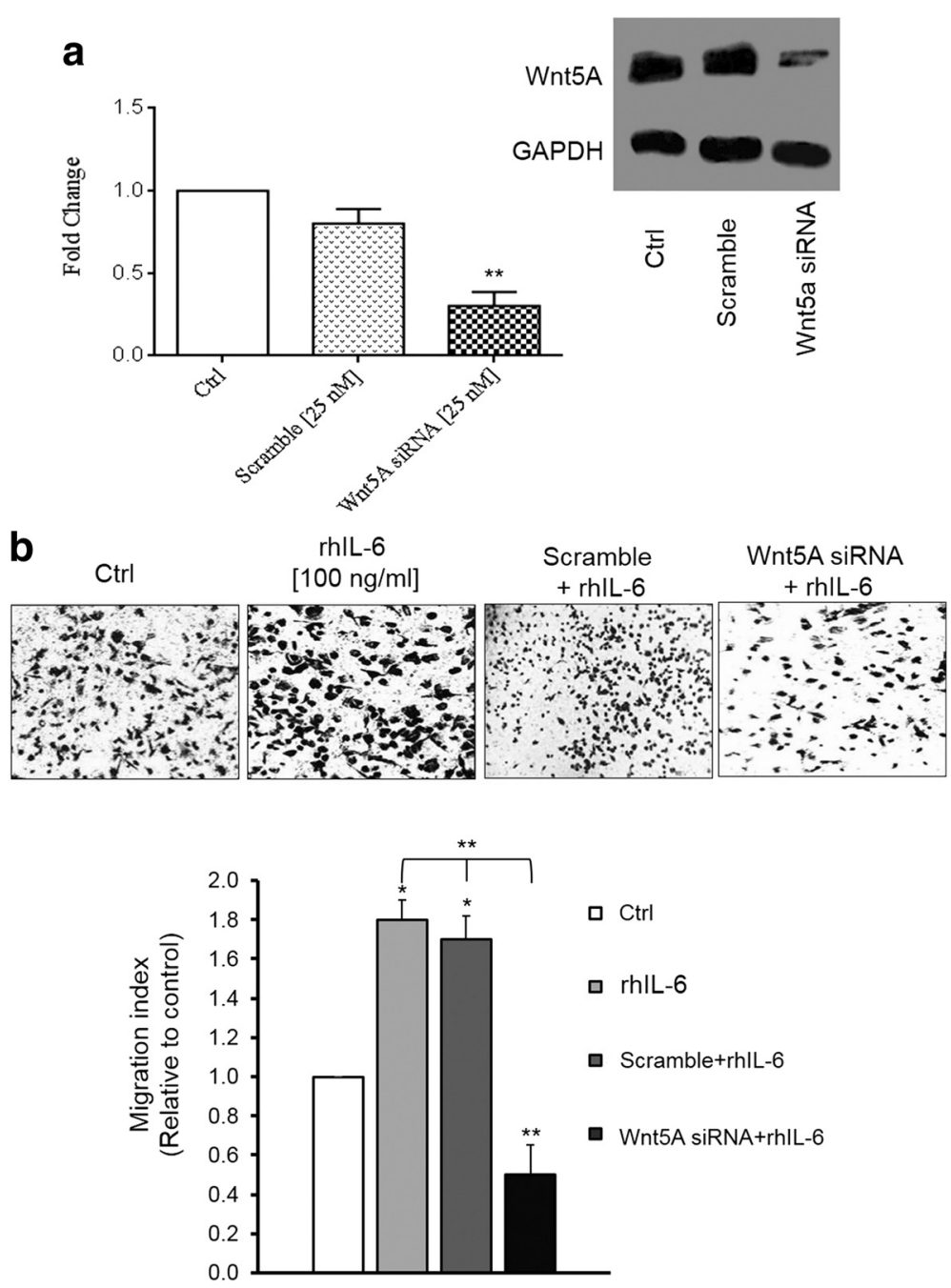

Fig. 6 Wnt5A is involved in rhlL-6-induced migration in SKOV-3 cells. a - Western blot quantification showed a $70 \%$ reduction in Wnt5A expression in siRNA Wnt5A-transfected cells compared with the controls. The western blots represent one of three independent experiments. GAPDH levels were used as the internal control. $\mathbf{b}$ - In vitro cell migration assay of non-transfected or siRNA Wnt5A-transfected cells in the absence or presence of rhlL-6. The upper panel showed photos of transwells in the indicated conditions and the lower panel showed quantification of migrated cells in ten random fields. The percentage of migrated cells was expressed as: (number of migrated cells/number of seeded cells $\times 100$ ). The migration index was expressed relative to control cells (set as $100 \%$ ). All of the experiments were carried out three times and the results are expressed as means \pm SD. Magnification: $100 x .{ }^{*} p \leq 0.05 ;{ }^{*} p \leq 0.0$ as compared with the control (Ctrl)

demonstrated that blockage of NF-kB activity in SKOV-3, ip1 and HEYA8 ovarian cancer cells can reduce tumor growth in xenograft mice [41]. In addition, blockage of the JAK/STAT3 pathway inhibited ovarian cancer cell growth [42]. In agreement with these findings, we found here that NF-kB and STAT3 inhibitors decrease SKOV-3 cell viability.

It was intersting to find that both NF-kB and STAT3 inhibitors decrease Wnt5A expression in a time-dependent manner. However, our data showed that blockage of STAT3 activation has the strongest effect on the modulation of Wnt5A and ROR2 expression compared to treatment of cells with NF-kB inhibitor. 

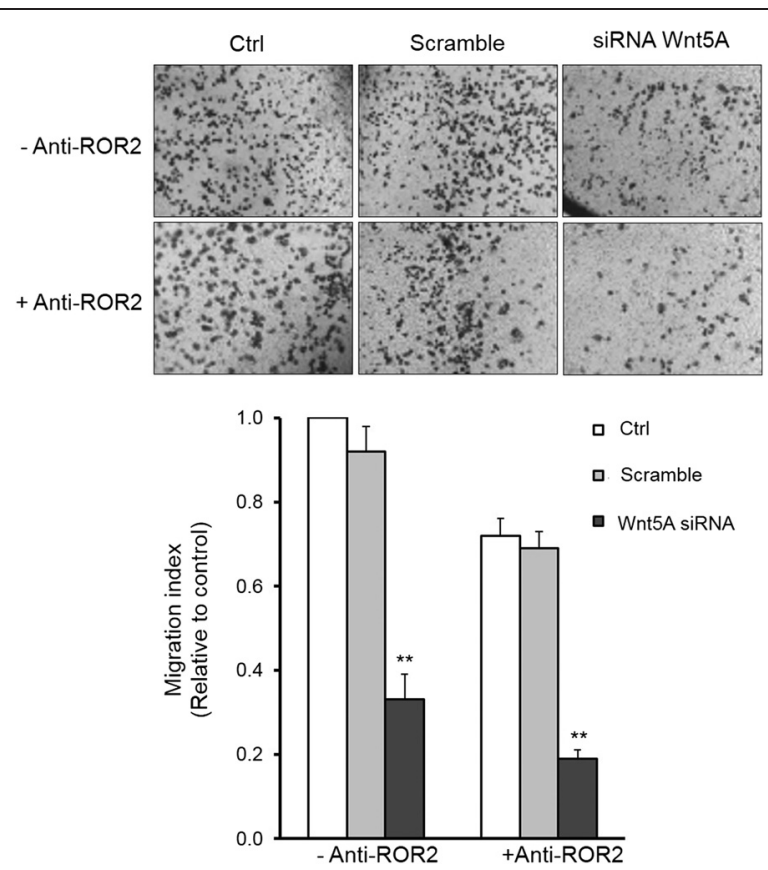

Fig. 7 Wnt5A-ROR2 is implicated in SKOV-3 cell migration. a - In vitro cell migration assay of non-transfected or siRNA Wnt5A-transfected cells in the absence or presence of anti-ROR2 antibody. The upper part or photos shows photos of transwells with the indicated conditions. The graph shows quantification of counted migrated cells in ten random fields. All of the experiments were carried out three times and the results are expressed as means \pm SD. Magnification: 100x. ${ }^{* *} p \leq 0.01$ as compared with the control (Ctrl)

This is the first report showing the expression of ROR2 in SKOV-3 cells and its modulation by inflammatory mediators. Similar to Wnt5A, ROR2 expression was increased by LPS, LTA and IL-6. Its expression was moderately decreased by the NF-kB inhibitor but strongly blocked by the presence of STAT3 inhibitor.

Although Wnt5A-ROR2 expression was regulated by both NF-kB and STAT3, only LPS- and LTA-induced Wnt5A-ROR2 increases were completely abrogated by STAT3 inhibitor. The IL-6-induced Wnt5A increase was abrogated in the presence of STAT3 inhibitor, but IL-6-induced ROR2 was only moderately decreased with the STAT3 inhibitor. We can not exclude the possibility that IL-6 may trigger other signaling pathways that further influence ROR2 expression. It should be noted that to date there was no report on the existence of an NF-kB- or STAT3-binding site in the ROR2 promoter.

Interestingly, we observed that Wnt5A levels regulate ROR2 expression level. This means that following downregulation of Wnt5A expression, there was strong decrease in ROR2 expression levels (unpublished data). This is also supported by our data showing that the ROR2 response to inflammatory mediators takes more time than the Wnt5A response. This may suggest that the effect of NF-kB and STAT3 on ROR2 modulation could be mediated indirectly via Wnt5A levels. A downstream Wnt5A target that affects ROR2 expression levels remains unknown.

Two mechanisms are under consideration for the strongest effect of the STAT3 inhibitor on the Wnt5A-ROR2 expression level. As SKOV-3 cells have NF-kB constitutive activation [43], one possibility is that activated STAT3 in these cells can ensure constitutive NF-kB activation [44]. Another mechanism may be that once in the nucleus, the NF-kB-STAT3 complex can bind to unique Wnt5A or ROR2 DNA target 
sequences to which neither factor can bind on its own. These hypotheses warrants furher experiments.

It is well known that inflammation mediates cancer cell migration [3]. In our previous study, we showed that Wnt5A induced SKOV-3 cell migration [16]. It has been reported that IL-6 promotes EOC cell proliferation, migration and invasion [45, 46]. Here, we showed that Wnt5A is involved in IL-6 increases in cell migration.

\section{Conclusions}

Our data showed for the first time that Wnt5A-ROR2 is modulated by inflammatory mediators and inflammatory pathways, and this prompted us to assess the role of Wnt5A-ROR2 in ovarian cancer migration. This is the first report showing that ROR2 signaling is implicated in Wnt5A-induced cell migration, which corroborates the finding of Nishita et al. [47] in other cancer cells. The findings of this study may provide new insight into the role of Wnt5A-ROR2 in ovarian cancer progression and help in the development of further targeted drugs for ovarian cancer treatment.

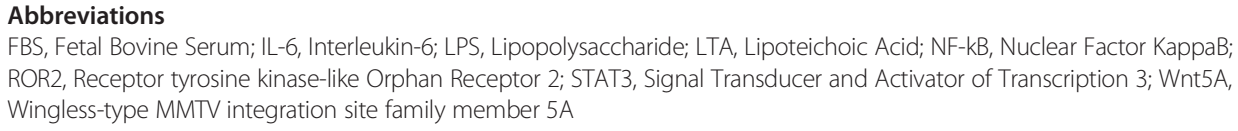

FBS, Fetal Bovine Serum; IL-6, Interleukin-6; LPS, Lipopolysaccharide; LTA, Lipoteichoic Acid; NF-kB, Nuclear Factor KappaB; ROR2, Receptor tyrosine kinase-like Orphan Receptor 2; STAT3, Signal Transducer and Activator of Transcription 3; Wnt5A, Wingless-type MMTV integration site family member 5A

\section{Acknowledgments}

We are grateful to the personnel of the Avicenna Research Institute (ACECR) with special thanks to Ms. Hale Edalatkhah for her assistance with the GPCR instrument and analyses.

\section{Funding}

This work was supported in part by grant \# 263808/6D/21from College of Science, University of Tehran and grant \# 90007348 from Iranian national foundation of science (INFS), Tehran, Iran.

Availability of data and materials

The datasets supporting the conclusion of this article are included within the article.

\section{Authors' contributions}

SA participated conducted the experiments and data analysis and contributed to the writing the manuscript. $\mathrm{GH}$ conceived the idea, designed the study and contributed to thedata nalysis and writing of the manuscript. ZSD performed cell migration assay. AHS was involved with study design and discussion of the data. All authors read and approved the final manuscript.

\section{Competing interests}

The author declares that they have no competing interests.

\section{Consent for publication}

Not applicable.

Ethics approval and consent to participate

Not applicable.

\section{Author details}

'Department of Animal Physiology, Developmental Biology Laboratory, School of Biology, College of Science, University of Tehran, Tehran, Iran. '2Nanobiotechnology Research Center, Avicenna Research Institute, ACECR, Tehran, Iran. ${ }^{3}$ Immunology Research Center, Iran University of Medical Sciences, Tehran, Iran.

Received: 11 September 2015 Accepted: 8 December 2015

Published online: 28 July 2016

\section{References}

1. World Cancer Report 2014. International Agency for Research on Cancer

2. Ozols RF, Bookman MA, Connolly DC, Daly MB, Godwin AK, Schilder RJ, et al. Focus on epithelial ovarian cancer. Cancer Cell. 2004:5:19-24.

3. Atsumi T, Singh R, Sabharwal L, Bando H, Meng J, Arima Y, et al. Inflammation Amplifier, a New Paradigm in Cancer Biology. Cancer Res. 2014;74:8-14.

4. Logan CY, Nusse R. The Wnt signaling pathway in development and disease. Annu Rev Cell Dev Biol. 2004;20:781-810. 
5. Minami Y, Oishi I, Endo M, Nishita M. Ror family receptor tyrosine kinases in noncanonical Wnt signaling: their implications in developmental morphogenesis and human diseases. Dev Dyn. 2010;239:1-15.

6. Nishita M, Enomoto M, Yamagata K, Minami Y. Cell /tissue-tropic functions of Wnt5a signaling in normal and cancer cells. Trends Cell Biol. 2010;20:346-54.

7. Blumenthal A, Ehlers S, Lauber J, Buer J, Lange C, Goldmann T, et al. The Wingless homolog WNT5A and its receptor Frizzled-5 regulate inflammatory responses of human mononuclear cells induced by microbial stimulation. Blood. 2006;108:965-73.

8. Pereira C, Schaer DJ, Bachli EB, Kurrer MO, Schoedon G. Wnt5A/CaMKIl signaling contributes to the inflammatory response of macrophages and is a target for the anti-inflammatory action of activated protein $\mathrm{C}$ and interleukin10. Arterioscler Thromb Vasc Biol. 2008;28:504-10.

9. Mikels AJ, Nusse R. Purified Wnt5a protein activates or inhibits beta-catenin-TCF signaling depending on receptor context. PLoS Biol. 2006;4:115.

10. O'Connell MP, Fiori JL, Xu M, Carter AD, Frank BP, Camilli TC, et al. The orphan tyrosine kinase receptor, ROR2, mediates Wnt5a signaling in metastatic melanoma. Oncogene. 2010;29:34-44.

11. Enomoto M, Hayakawa S, Itsukushima S, Ren DY, Matsuo M, Tamada K, et al. Autonomous regulation of osteosarcoma cell invasiveness by Wnt5a /Ror2 signaling. Oncogene. 2009;28:3197-208.

12. Wright TM, Brannon AR, Gordan JD, Mikels AJ, Mitchell C, Chen S, et al. Ror2, a developmentally regulated kinase, promotes tumor growth potential in renal cell carcinoma. Oncogene. 2009;28:2513-23.

13. Yamamoto H, Oue N, Sato A, Hasegawa Y, Yamamoto H, Matsubara A, et al. Wnt5a signaling is involved in the aggressiveness of prostate cancer and expression of metalloproteinase. Oncogene. 2010;29:2036-46.

14. Kurayoshi M, Oue N, Yamamoto H, Kishida M, Inoue A, Asahara T, et al. Expression of Wnt-5a is correlated with aggressiveness of gastric cancer by stimulating cell migration and invasion. Cancer Res. 2006;66:10439-48.

15. Ripka S, König A, Buchholz M, Wagner M, Sipos B, Klöppel G, et al. WNT5A-target of CUTL1 and potent modulator of tumor cell migration and invasion in pancreatic cancer. Carcinogenesis. 2007;28:1178-87.

16. Jannesari-Ladani F, Hossein G, Monhasery N, Shahoei SH, Izadi MN. Wnt5a Influences Viability, Migration, Adhesion, Colony Formation, E- and N-Cadherin Expression of Human Ovarian Cancer Cell Line SKOV-3. Folia Biol. 2014;60:57-67.

17. Katula KS, Joyner-Powell NB, Hsu CC, Kuk A. Differential Regulation of the Mouse and Human Wnt5a Alternative Promoters A and B. DNA Cell Biol. 2012;3:1585-97.

18. Katoh M, Katoh M. STAT3-induced WNT5A signaling loop in embryonic stem cells, adult normal tissues, chronic persistent inflammation, rheumatoid arthritis and cancer (Review). Int J Mol Med. 2007;19:273-8.

19. He F, Xiong W, Yu X, Espinoza-Lewis R, Liu C, Gu S, et al. Wnt5a regulates directional cell migration and cell proliferation via Ror2-mediated noncanonical pathway in mammalian palate development. Development. 2008; 135:3871-9.

20. Sen M, Chamorro M, Reifert J, Corr M, Carson DA. Blockade of Wnt-5A/frizzled 5 signaling inhibits rheumatoid synoviocyte activation. Arthritis Rheum. 2001;44:772-81.

21. Bergenfelz C, Medrek C, Ekstro $m$ E, Jirstro $m$ K, Janols H, Wullt xM, et al. Wnt5a Induces a Tolerogenic Phenotype of Macrophages in Sepsis and Breast Cancer Patients. J Immunol. 2012;188:5448-58.

22. Kim J, Chang W, Jung Y, Song K, Lee I. Wnt5a activates THP-1 monocytic cells via a $\beta$-catenin-independent pathway involving JNK and NF-kB activation. Cytokine. 2012;60:242-8.

23. Jung YS, Lee HY, Kim SD, Park JS, Kim JK, Suh PG, et al. Wnt5a stimulates chemotactic migration and chemokine production in human neutrophils. Exp Mol Med. 2013;45:e27.

24. Kim J, Kim J, Kim DW, Ha Y, Ihm MH, Kim H, et al. Wnt5a Induces Endothelial Inflammation via $\beta$-Catenin Independent Signaling. J Immunol. 2010;185:1274-82.

25. Zhao Y, Zhang C, Huang Y, Yu Y, Li R, Li M, et al. Upregulated Expression of WNT5a Increases Inflammation and Oxidative Stress via PI3KJAKT/NF-KB Signaling in the Granulosa Cells of PCOS Patients. J Clin Endocrinol Metab. 2015;100:201-11.

26. Ge XP, Gan YH, Zhang CG, Zhou CY, Ma KT, Meng JH, et al. Requirement of the NF-kappaB pathway for induction of Wnt-5A by interleukin-1 beta in condylar chondrocytes of the temporomandibular joint: functional crosstalk between the Wnt-5A and NF-kappaB signaling pathways. Osteoarthr Cartilage. 2011;19:111-7.

27. Rauner M, Stein N, Winzer M, Goettsch C, Zwerina J, Schett G, et al. WNT5A is induced by inflammatory mediators in bone marrow stromal cells and regulates cytokine and chemokine production. J Bone Miner Res. 2012;27:575-85.

28. Zhou M, Macfarland-Mancini MM, Funk HM, Husseinzadeh N, Mounaj- jed T, Drew AF. Toll-like receptor expression in normal ovary and ovarian tumors. Cancer Immunol Immuno Ther. 2009;58:1375-85.

29. Syed V, Ulinski G, Mok SC, Ho SM. Reproductive hormone-induced, STAT3-mediatedinterleukin 6 action in normal and malignant human ovarian surface epithelial cells. J Natl Cancer Inst. 2002;94:17-629.

30. Wang Y, Niu XL, Qu Y, Wu J, Zhu YQ, Sun WJ, et al. Autocrine production ofinterleukin-6 confers cisplatin and paclitaxel resistance in ovarian cancer cells. Cancer Lett. 2010;295:110-23.

31. Chen R, Alvero AB, Silasi DA, Kelly MG, Fest $S$, Visintin I, et al. Regulation of IKK $\beta$ by miR-199aaffects NF-kB activity in ovarian cancer cells. Oncogene. 2008;27:4712-23.

32. Annunziata CM, Stavnes HT, Kleinberg L, Berner A, Hernandez LF, Birrer MJ, et al. Nuclear factor kB transcription factors are coexpressed and convey a poor outcome in ovarian cancer. Cancer. 2010;116:3276-84.

33. Ford CE, Punnia-Moorthy G, Henry CE, Llamosas E, Nixdorf S, Olivier J, et al. The non-canonical Wnt ligand, Wnt5A, is upregulated and associated with epithelial to mesenchymal transition in epithelial ovarian cancer. Gynecol Oncol. 2014;134:338-45.

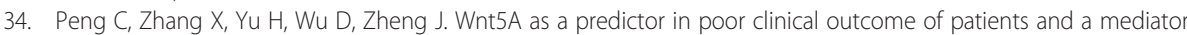
in chemoresistance of ovarian cancer. Int J Gynecol Cancer. 2011;21:280-8.

35. Filho LB, Oshima CT, De Oliveira LF, De Oliveira CH, De Sousa DR, Gomes TS, et al. Canonical and noncanonical Wnt pathway: A comparison among normal ovary, benign ovarian tumor and ovarian cancer. Oncology Rep. 2009:21:313-20. 
36. Matei D, Graeber TG, Baldwin RL, Karlan BY, Rao J, Chang DD. Gene expression in epithelial ovarian carcinoma. Oncogene. 2002;21:6289-98.

37. Bitler BG, Nicodemus JP, Li H, Cai Q, Wu H, Hua X, et al. Wnt5a Suppresses Epithelial Ovarian Cancer by Promoting Cellular Senescence. Cancer Res. 2011;71:6184-94.

38. Asgharzadeh S, Pique-Regi R, Sposto R, Wang H, Yang Y, Shimada $H$, et al. Prognostic significance of gene expression profiles of metastatic neuroblastomas lacking MYCN gene amplification. J Natl Cancer Inst. 2006; 98:1193-203.

39. Mabuchi S, Ohmichi M, Nishio Y, Hayasaka T, Kimura A, Ohta T, et al. Inhibition of NFkappaB increases the efficacy of cisplatin in in vitro and in vivo ovarian cancer models. J Biol Chem. 2004;279:23477-85.

40. Mabuchi S, Ohmichi M, Nishio Y, Hayasaka T, Kimura A, Ohta T, et al. Inhibition of inhibitor of nuclear factorkappaB phosphorylation increases the efficacy of paclitaxel in in vitro and in vivo ovarian cancer models. Clin Cancer Res. 2004;10:7645-54.

41. Huang S, Robinson JB, Deguzman A, Bucana CD, Fidler IJ. Blockade of nuclear factor-kappaB signaling inhibits angiogenesis and tumor-igenicity of human ovarian cancer cells by suppressing expression of vascular endothelial growth factor and interleukin 8. Cancer Res. 2000;60:5334-9.

42. Gritsina G, Xiao F, O'Brien SW, Gabbasov R, Maglaty MA, Xu RH, et al. Targeted Blockade of JAK/STAT3 Signaling Inhibits Ovarian Carcinoma Growth. Mol Cancer Ther. 2015;14:1035-47.

43. Liu GH, Wang SR, Wang B, Kong BH. Inhibition of nuclear factor-kappaB by an antioxidant enhances paclitaxel sensitivity in ovarian carcinoma cell line. Int J Gynecol Cancer. 2006;16:1777-82.

44. Lee H, Herrmann A, Deng JH, Kujawski M, Niu G, Li Z, et al. Persistently activated STAT3 maintains constitutive NF-kappaB activity in tumors. Cancer Cell. 2009;15:283-93.

45. Obata NH, Tamakoshi K, Shibata K, Kikkawa F, Tomoda Y. Effects of interleukin-6 on in vitro cell attachment, migration and invasion of human ovarian carcinoma. Anticancer Res. 1997:17:337-42.

46. Wang Y, Li L, Guo X, Jin X, Sun W, Zhang X, et al. Interleukin-6 signaling regulates anchorage-independent growth, proliferation, adhesion and invasion in human ovarian cancer cells. Cytokine. 2012;59:228-36.

47. Nishita M, Yoo SK, Nomachi A, Kani S, Sogawa N, Ohta Y, et al. Filopodia formation mediated by receptor tyrosinekinase Ror2 is required for Wnt5A-inducedcell migration. J Biol Chem. 2006;175:555-62.

\section{Submit your next manuscript to BioMed Central and we will help you at every step:}

- We accept pre-submission inquiries

- Our selector tool helps you to find the most relevant journal

- We provide round the clock customer support

- Convenient online submission

- Thorough peer review

- Inclusion in PubMed and all major indexing services

- Maximum visibility for your research

Submit your manuscript at www.biomedcentral.com/submit 